\title{
Series and Parallel Demand Sharing in Multi-Boiler System
}

\author{
Suyog. S. Bajaj ${ }^{*}$, S. H. Barhatte ${ }^{\dagger}$ and S. U. Shinde ${ }^{\dagger}$ \\ †Department of Mechanical Engineering, Savitribai Phule Pune University, MIT College of Engineering, Pune India \\ Accepted 02 March 2016, Available online 15 March 2016, Special Issue-4 (March 2016)
}

\begin{abstract}
A boiler is an enclosed vessel that provides a means for heat of combustion to be transferred into water until it becomes heated water or steam. The hot water or steam under pressure is then usable for transferring the heat to a process. The requirement of steam or hot water i.e. process requirements keep on varying throughout the day. This also implied that load on the boiler may not be same at all the time. Therefore, more than two boilers of different capacities can be operated. A suitable combination of boilers can be chosen to get the desired load. Such a system, generally called as multi-boiler system can be used to improve the efficiency of the plant as a whole. Boiler can be connected in series or parallel. This reduces the overall running cost of the plant.
\end{abstract}

Keywords: Multi-boiler system, demand sharing, series and parallel combination

\section{Introduction}

A steam plant consists of four main components, boiler, turbine, condenser and feed pump. The boiler is used to convert the water to steam by taking heat from combustion of fuel. Steam with high pressure and temperature is directed to push turbine blades mounted on the shaft, so the shaft rotates. This steam then flows to the condenser, while the rotary power is used to turn a generator. Alternatively it is also used in process industry like sugar, paper, fertilizer, textile, etc. The main task of an industrial steam power plant is to produce process steam required by the generator or plant's processes. This means that, even when there is varying steam usage, there must always be sufficient steam available for those processes. The steam quality, pressure and temperature need to be maintained, within acceptable limits, as the power plant's output adjusts to changes in electricity and process steam demands. To achieve maximum efficiency of the plant, it is important that the steam production matches the steam demand as accurately as possible, and the power plant can react quickly to the changing demand requirements. Effective boiler control becomes necessary because the boiler does not have same efficiency for all load condition.

When single boiler is considered this control is comparatively easy. But many facilities have more than one boiler on-site running because of the advantages obtained from multiple boiler system. It is essential to maintain and upgrade the boiler control systems to assure steam availability.

*Corresponding author: Suyog. S. Bajaj
When using a multiple boiler system in a steam plant, the demand-load management is important to get the optimum results. As the efficiency of boiler changes with load, it is very difficult to identify the optimal load distribution to maximize the efficiency of the steam plant. As no common strategy exists, the operation \& load distribution among the boilers are left on the expertise \& experience of boiler operator. This results in significant loss in efficiency \& operating cost. Demand-load management is an optimizing function that augments the combustion-control system. Both the methods are used effectively to achieve an overall optimization of a steam plant.

The plant which utilizes steam has varying demands. When steam demand is low the boiler efficiency falls down. To improve the efficiency and to meet the varying demand optimally, it is suggested that multiple small packaged boilers should be used with proper demand load management. The use of such packaged boilers saves the consumption of fuel and also saves on the space required for installation.

The use of multiple boilers needs demand-share arrangement. The demand-share arrangement allows each boiler to be operated in either base load or modulating service, finding the best distribution of load between the boilers that will result in the lowest overall cost. The base-load operation leaves the implementation up to the operator. In this mode, the total demand is shared between the base-load boilers in proportion to the operator set base-load values. The modulating mode of operation, on the other hand, enforces automatically the load allocation without the need for operator intervention. The total demand, less that satisfied by the base-load boilers, is shared 
between the modulating boilers in proportion to their capacities. The flexibility of the control module is such that one combination of boiler modes can be applied dynamically tithe boiler plant. (A.R.C. Tuck and W.L.H. Hallett, et al, 2012)

In boiler plants, the most effective load allocation is not based on a simple operating decision but on realtime calculations taking into account the following:

- Operating safety margins

- Load fluctuations

- Required shut-down characteristics

- Boiler capacities

A further important decision involves the demand sharing methodology, which can be either parallel or series, depending on plant requirements.

\section{Boiler System}

A boiler is an enclosed vessel that provides a means for combustion heat to be transferred into water until it becomes heated water or steam. The hot water or steam under pressure is then usable for transferring the heat to a process. Major losses occurring in the boilers are stack loss, unburned fuel loss, and radiation loss. To achieve maximum efficiency these losses have to be maintained at minimum level. The primary purpose of any boiler control system is to manipulate the firing rate so that the supply of steam remains in balance with the demand for steam over the full load range. In addition, it is necessary to maintain an adequate supply of feed water and the correct mixture of air and fuel for safe and economical combustion. As the load falls, so does the value of the mass flow rate of the flue gases through the tubes. This reduction in flow rate for the same heat transfer area, results in lower flue gas exit temperature and lower sensible heat loss. The maximum efficiency of the boiler does not occur at full load, but at about two-thirds of the full load. If the load on the boiler decreases further, efficiency also tends to decrease because, reduction in flow rate also results in lower degree of turbulence and subsequent increase in excess air requirement for complete combustion. This results in higher sensible heat loss. Lower load also results in increase in percentage radiation loss, as the same surface area is exposed for surface radiation. Due to these behaviors, efficiency initially increases with decrease in load and then decreases. The effective output of boiler also depends on selection of right boiler for a particular purpose. Boilers are manufactured in various designs and sizes, depending on characteristics of the fuel used and the heating output. Some boilers are only capable of producing hot water while others are designed to produce steam. The basic purpose of a boiler is to convert chemical energy into thermal energy. (M.W. van de Weerdhof, et al; Martin Miltner et al, 2006)

\section{Control Systems}

Dynamic behaviour of a boiler accompanying with improper control systems may cause damage to the boiler. Sudden increase or decrease in the steam demand causes corresponding reduction and increase in the steam pressure inside the boiler respectively. This pressure causes swell and shrink phenomenon on the water side. Improper management of pressure and water level makes control systems to work in wrong direction and with some inherent time lag.The efficiency of a boiler system is important in several ways. The constantly rising cost of fuel used means that by increasing the efficiency by several percent, substantial savings can be made on a yearly basis. By maximizing the amount of energy extracted from the fuel, not only does the fuel usage decrease and thereby reduce cost but it also has a significant effect on the emissions from the system. Improving the efficiency of the combustion process can severely reduce the amount of harmful compounds in the flue gas. (K. J. Astrom, R. D. Bell, et al, 2009 ; Mehdi Parsa, Ali Vahidian Kamyad and Mohammad Bagher Naghibi Sistani, et al, 2004)

\section{Control Strategy in Multiple Boiler System}

In a multi-boiler plant, demand-load management optimizes the distribution of steam demand among the units and adjusts the overall output to meet working requirements. One of the strategies used for load management is Parallel or Series Demand Sharing.

In parallel demand sharing, the available boilers share the total demand simultaneously by taking up an equal firing rate to meet the load. On load increase, the firing rate of all modulating boilers will increase equally until the load requires an additional boiler. At this point, the firing rate of the active boilers decreases to compensate for the firing rate of the newly started boiler. Figure 1 explains the process for an increase of load. Parallel modulation is generally implemented for steam boilers. It offers the most effective control when relatively steady process loads are available. As the system modulates the boiler plant to adjust the common header pressure to the required set point, a smoother response to changing load conditions is performed by the controller.

Series demand sharing allocates loads by normally forcing one boiler at a time to modulate in order to satisfy the demand and is most effective when used with the Euro herm demand schedule control module. On load increase, the firing rate of the modulating boiler will increase until the load requires an additional boiler. At this point, a new boiler is started and becomes the modulating boiler. The other active boilers are ramped to their optimum firing rate. Figure 2 explains the process for an increase of load. Series modulation is generally implemented for hot water systems or fluctuating steam loads. This mode allows faster individual boiler response to plant conditions as the boiler pressure is adjusted to the required set point. To decide the optimum strategy for incorporating multiple boilers in steam plant two strategies for the demand load management i.e. series 
and parallel are considered. (Hjalti Kristinsson, Sofie Lang, et al, 2010)

Strategy 1: The two boilers where one of the boilers is operating at maximum load and the other boiler is operating with modulating load to meet the demand fluctuations. This is known as series demand load management. The boiler one operating at fixed maximum load has maximum firing rate i.e. it uses maximum fuel for combustion. This is called as the lead boiler. The modulating boiler adjusts its fuel firing rate according to requirement. This one is called as lag boiler. The total fuel consumed to meet the requirement of plant is calculated as follows

Total fuel fired $=(\text { fuel fired in lead boiler })_{\text {maximum }}+($ fuel fired in lag boiler) modulating $_{\text {m }}$

As the boiler one is operating at maximum load utilizing its full capacity the steam delivered by this boiler will be equal to its maximum quantity. Thus while deciding the load on next boiler this maximum steam quantity is deducted from the total steam demand.

Load on lag boiler $=($ total load $)-($ load on lead boiler $)$

Strategy 2: For the same two boilers next strategy is employed i.e. parallel load management. In this case both the boilers are fired equally and both the boilers are modulating to meet the demand of plant as per requirement. Unlike series management this method does not have one lead and one lag boiler but both the boilers distribute the load equally. It is known that the efficiency of boiler is maximum not at the maximum load but at the two third of the total load. So if both the boilers are operated at a load less than maximum load, increase in the efficiency is expected. The fuel fired for the two modulating boilers is calculated and the summation gives the total fuel fired to produce required steam.

Total fuel fired $=(\text { fuel fired in boiler } 1)_{\text {modulating }}+($ fuel fired in boiler2) modulating

Both the boilers here are equally fired and so the load is equally distributed on these boilers.

Load on boiler $1=$ Load on boiler $2=\left(0.5^{*}\right.$ Total load $)$

After these two strategies are developed, they are analyzed with two cases of increasing load condition and decreasing load condition. The results in both cases for these strategies are compared and final conclusion is drawn. In the parallel strategy, the load on boilers increases or decreases simultaneously when the demand increases or decreases. But this is not the case for series strategy and its explained below.
Case 1

Initially the lead boiler is operating at the $100 \%$ load and the modulating boiler is operating at its minimum load. As the demand of steam requirement increases the load on modulating boiler increases beyond minimum value.

\section{Case 2}

As the load requirement in plant decreases the load on the modulating boiler decreases first until it reaches its minimum value for that boiler. Later the load on lead boiler starts decreasing till the total output from boilers equal the total demand.

\section{Experimentation Results}

So far, experimentation done on two boiler having capacity $15 \mathrm{TPH}$ and $18 \mathrm{TPH}$ the following results are obtained.

Two strategies were developed for load management and studied under this project namely,

- $\quad$ Series demand load management

- Parallel demand load management

Table 1: Fuel Consumption for Various Strategies and Conditions in Multiple Boiler System

\begin{tabular}{|c|c|}
\hline Case & Fuel consumption \\
\hline 1. Increasing load & \\
\hline - Series strategy & $4067 \mathrm{~kg}$ \\
\hline - Parallel strategy & $4292 \mathrm{~kg}$ \\
\hline 2. $\quad$ Decreasing load & \\
\hline - Series strategy & $1822 \mathrm{~kg}$ \\
\hline - Parallel strategy & $1942 \mathrm{~kg}$ \\
\hline
\end{tabular}

Case 1: Here the multiple boiler system is analysed under the increasing load condition.

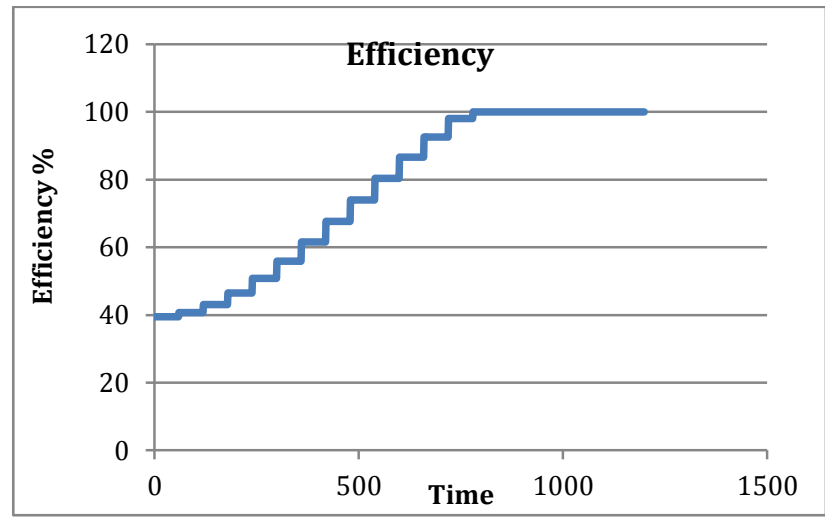

Fig.1 Efficiency of two boiler system with respect to time (Series strategy) 


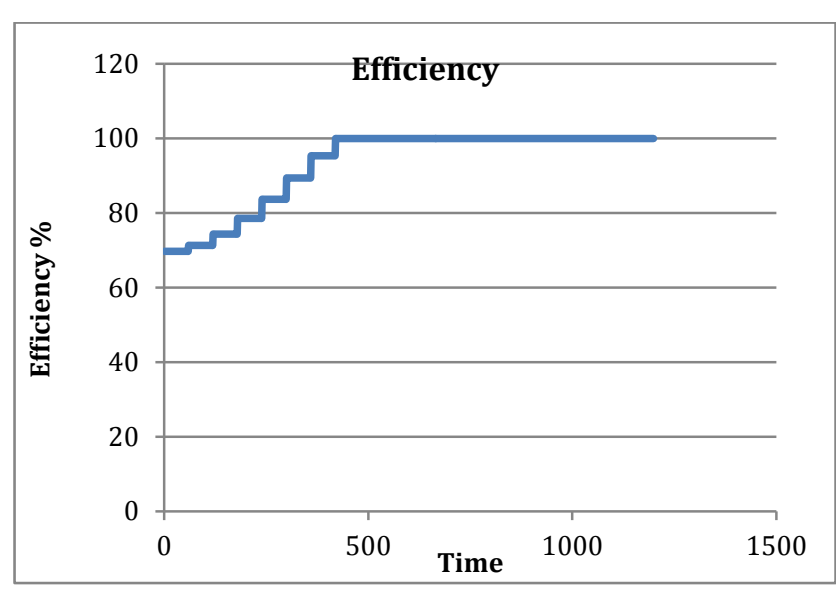

Fig.2 Efficiency of two boiler system with respect to time (Parallel strategy)

Case 2: Here the multiple boiler system is analysed under the decreasing load condition.

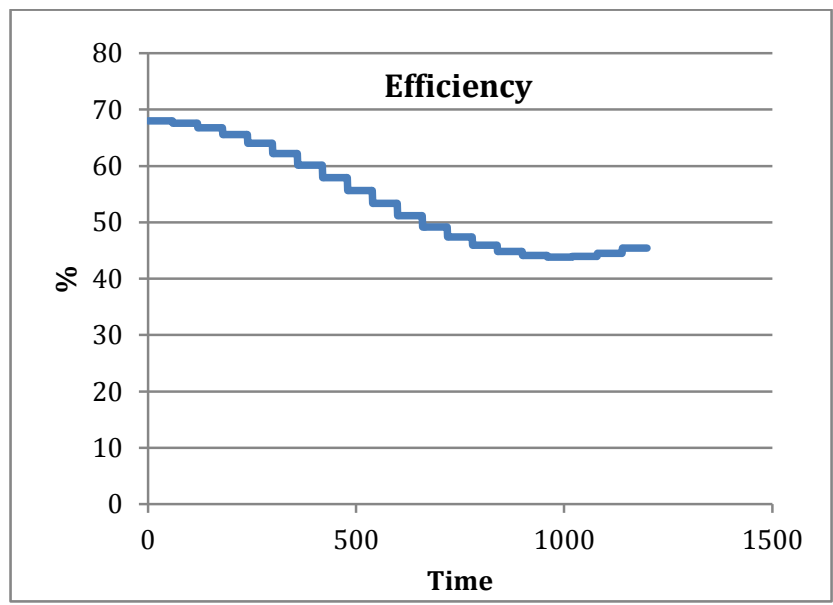

Fig.3 Efficiency of Two Boiler System with Respect to Time (Series Strategy)

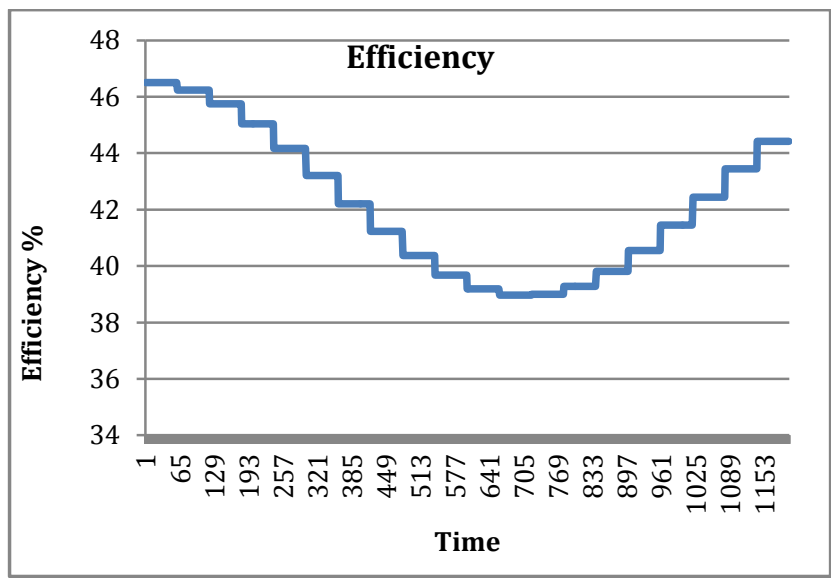

Fig.4 Efficiency of Two Boiler System with Respect to Time (Parallel Strategy)

\section{Conclusions}

1) The fuel consumption is less for the series type of load management as compared to the parallel type load management. Thus, we can ensure economic operation of multiple boilers in a steam plant when operated with series strategy.

2) When boiler are connected in series its fuel consumption decreases by $5.5 \%$ under increasing load demand and by $6.5 \%$ under decreasing load demand as compare to parallel system.

3) The variation in efficiency of multiple boiler system, when operated in series and parallel. When operating at part load conditions, the parallel strategy for multiple boiler system gives better efficiency than the series strategy.

4) Hence the optimum solution for operation of multiple boiler system in steam plant is to operate with series load management strategy.

\section{References}

Lasse Rosendah, et.al, (2007), Development of Generalised Model for Grate Combustion of Biomass, Institue of Energy Technology,Aalborg University.

M.W. van de Weerdhof, Modelling the Pyrolysis Process of Biomass Particles, Eindhoven University of Technology.

A.R.C. Tuck and W.L.H. Hallett (2012), Modelling of Particle Pyrolysis in a Packed Bed Combustor, Depts. of Chemical and Mechanical Engineering, University of Ottawa, Ottawa, Ontario K1N 1 C8.

Martin Miltner et. al, (2006), CFD-Modelling for the Combustion of Solid-Baled Biomass, Fifth International Conference on CFD in the Process Industries CSIRO, Melbourne, Australia 13-15.

K. J. Astrom, R. D. Bell, (2009), Drum-boiler dynamics, Department of Automatic Control, Lund Institute of Technology, Box 118, S-221 00 Lund, Sweden,"Department of Computing, School of Mathematics, Physics, Computing and Electronics, Macquarie University, New South Wales 2109, Australia.

Mehdi Parsa, Ali Vahidian Kamyad and Mohammad Bagher Naghibi Sistani (2004), Combustion Efficiency Optimization By Adjusting The Amount Of Excess Air, Department Of Electrical Engineering,Ferdowsi University of Mashhad Iran.

Hjalti Kristinsson, Sofie Lang (2010), Boiler Controlimproving efficiency of boiler systems. Lund University, Faculty of Engineering Division of Industrial Electrical Engineering and Automation AB Regin

K. Sorensen, et.al (2003), Modelling and simulating fire tube boiler performance, Proceeding from SIMS, 44th conference on Simulation and Modelling, Session 2b,Lecture 7 . 